\title{
The Influence of Cross Cultural Communication on Chinese, Japanese and Korean Fashion Design
}

\begin{abstract}
Yuan Ling
School of communication, Wuhan Textile University, Wuhan, Hubei, China

1115813658@qq.com

ABSTRACT

As an important way of input and output between different cultures, cross-cultural communication is an important driving force for cultural integration. In the field of fashion design, cross-cultural communication enables countries and nations to learn from each other about design concepts, crafts, styles, etc., forming a benign interaction of the industry. In the period when China dominated the East Asian culture, Chinese traditional culture had a profound impact on the fashion design concept and technology of Japan, Korea and other countries. At present, Japan and South Korea, which are the first developed countries, are feeding back China's clothing design with their leading clothing industry and film and television industry, and even driving the comprehensive development of China's clothing industry. This phenomenon shows that cross-cultural communication is an important force to promote the sustainable development of the clothing industry, and the national strength determines who can become the subject of cultural output and the object of cultural input.
\end{abstract}

Keywords: cross cultural communication, traditional culture, fashion design

\section{跨文化传播对中日韩服装设计的影响}

\author{
袁玲
}

武汉纺织大学传媒学院, 武汉, 湖北, 中国
1115813658@qq.com

\section{摘要}

跨文化传播作为不同文化间相互输入和输出的重要路径, 是文化交融的重要推动力量。在服装设计领域, 跨文 化传播使各个国家与民族能够相互学习设计理念、工艺、款式等, 形成产业的良性互动。在中国处于主导东亚 文化的时期，中国传统文化对日本、朝鲜等国的服装设计理念和服装设计工艺产生了深远的影响。而当代，率 先步入发达国家行列的日本和韩国又以领先的服装产业和影视业对中国的服装设计予以反哺，甚至带动了当 代中国服装产业的全面发展。这一现象表明, 跨文化传播是推动服装产业持续发展的重要力量, 而国力的强大 与否则决定了谁能够成为文化输出的主体和文化输入的客体。

关键词：跨文化传播，传统文化，服装设计

\section{1. 传统文化的传播对服装设计理念的影响}

传统文化是艺术与设计的底蕴, 跨文化传播则是 艺术设计不断革新的源动力。在同属东北亚地区的中 国、日本、韩国间，传统文化和影视文化的跨文化传 播是三个国家服装产业交替发展乃至齐头并进的重 要引擎。随着文化传播的程度逐步加深, 中、日、韩
的服装产业将会形成相互间良性影响的局面，且中国 将在未来通过多元化的传播路径输出更多的中国文 化，引导日本和韩国的服装产业发展。

中华民族有上下五千年的历史，其深厚的文化内 核影响着同属东北亚的日本和韩国。中国推崇的儒家 思想主张服装不仅要重华美也要重德馨，即“形式” 与 “内容” 需兼并, “文”与 与质”要并存，追求神形 
兼备、天人合一的美。这无疑使日本与韩国原本朴素 的服装受到巨大冲击, 为了跟上中国的审美脚步, 日、 韩人民开始学习中国思想与理念。

\section{1. 中日韩人民对传统服装的认知差异}

同属东北亚的中、日、韩三国人民对本民族传统 服装都很看重, 认为民族服装是传统文化的鬼力体现， 也尽力将传统服饰文化发扬光大。但由于历史文化与 地理条件的不同, 各国人民对传统服装的认知也存在 差异。在对民族服装的喜爱程度上, 日本人最高, 韩国 人其次，中国人则最低; 在对本民族传统文化的欣赏 程度上, 中国人则最高, 日本人其次, 韩国人最低。 中国与韩国人民将民族服装视为艺术品、认为本民族 服装需要创新、且有必要振兴本民族传统服装; 韩国 和日本人民明确地认为自己的民族服装属于高档礼 服, 中国人的态度则不明显; 日本人虽然认为和服价 格昂贵，但仍然持非常喜爱的态度，他们会在节假日 及重要场合穿着和服, 并将此看作是弘扬民族文化与 精神的行为。

中国有上下五千年深厚的历史文化底蕴，却并没 有公认的民族服装, 相对有代表性的传统服装就属汉 服和旗袍。其中汉服及汉服制度在 20 世纪以前一直 在东北亚地区占主导地位, 却并未作为中国传统民族 服饰文化完整留存。可见，日本、韩国人对民族服装 的喜好态度表现在具体行动上, 中国人则处在认识阶 段, 这需要相关人员在现有传统服饰基础上, 开发出 创新型的民族服装去满足人们的需求, 让民族服装真 正成为发扬民族传统、振兴民族精神和增强民族凝聚 力的有效载体。

\section{2. 中国传统文化输出对日韩服装设计理念 的影响}

日本与韩国曾是中国的附属国，其传统服装的原 型皆来自中国汉服。隋唐时期, 日本大量派遣唐史来 中国学习, 中国的服装制度与设计理念便由此传播至 日本。在儒家思想引导下，中国汉服反映的是华夏民 族遵循天道、进退权衡的信仰, 传统服饰注重天人合 一、神形兼备的理念对日本服饰朴素的设计理念造成 巨大冲击。中国包容、随和的民族态度在飘逸、酒脱 的汉服上展现的淋漓尽致, 使拘谨的日本人在对待服 装设计上有了改变。日本人在保留本土民族服饰特色 的基础上, 加入中国汉唐服饰的设计理念, 并在符合 日本审美的前提下对汉服款式加以改进, 逐渐形成现 在独特的和服文化。

而同属中国附属国的韩国，传统文化极少，大多 文化与制度都是模仿和学习中国。同样在儒家思想的 熏陶下, 韩国学习了中国礼仪制度后, 在韩服设计方 面也是以便于行礼和祭祀优先的设计理念为主, 而汉 服刚好满足了这一需求, 因此韩国人并未多做改良, 其韩服与汉服样式相差甚微。

\section{2. 传统文化的传播对服装设计工艺的影响}

中国作为东方最有影响力的文化之国，其传统文 明源远流长, 纺织技术、服饰色彩与图案的等级与象 征意义对世界各地影响颇大, 尤其是领土相邻的日本 与韩国。随着中国文化不断的跨国输出, 服装等级制 度与设计工艺都被带到日本与韩国, 并在两国的服装 设计方面产生了革命性的影响。

\section{1. 中国传统纺织技术输出对日韩服装制作 的影响}

汉族服饰在日本古坟时代就开始进入日本, 到奈 良时代, 也是中国最强盛的唐朝, 日本向中国大量派 遣 “遣唐使”, 学习中国的先进文化, 更是积极的引进 了中国服饰制度，中国的养蚕技术、织锦技术、绣花 技术也被带到日本, 使日本的养殖业与纺织业得到了 显著发展。

据《正仓院刊》记载: “唐代运去了彩色印花的锦、 绫、夹倾等高贵织物, 促使日本的丝织、漂印等技术 获得了启发。”在日本现代纺织印染的书籍中, 仍大量 沿用、罗、绫、羽、绞倾、蜡制等中国唐代的汉字名 称。且织物中的图案有织、绣、印等不同表现手法, 使上等的蚕丝面料呈现出不同的层次，锦上添花的服 饰工艺展现出盛唐时期的繁荣, 也成为日本学习与模 仿的对象。

早在春秋战国时期, 随着汉族人迁往朝鲜半岛, 汉服出现在了韩国人民视野中。韩国新罗时代, 新罗 道臣入唐学习汉服制度, 并完全沿用中国服装制, 即 “改其章服, 以从中华制”。与日本一样, 在学习中国 的服饰制度的同时, 养蚕、纺丝、与印染等技术也被 引进到韩国, 从此便诞生了由绫、罗、绸、䌸等高档 织物制作的韩服，成为韩国服装史上的一次面料大革 新。时至今日, 高档韩服仍沿用蚕丝作为主要面料, 成为重要节日与场合的最佳选择, 这也是韩国人认为 韩服是高档服装的原因之一。

\section{2. 中国传统文化输出对日韩服装款式与图 案的影响}

和服作为日本的传统服饰，在世界各地颇有名气。 但和服的最初形态只是在布中间开一个洞, 穿着时将 头从中穿过, 再用腰带加以固定即可。直到遣唐使将 汉服带回日本后, 日本吸取了汉服的优势, 又经过历 史的沿革才逐渐形成了如今独特的和服文化。在公元 701 年, 日本法律就明文规定要严格使用中国的着装 制度, 衣物的制作也要仿照中国服装的样式。根据这 一规定, 出入日本宫廷时必须穿朝服, 而且款式与配 饰也与唐代朝服基本一致。

在汉唐时期之前, 日本服装色彩单一, 同一种服 饰只有一个色调, 且几乎是没有图案的素服。中国自 古便有了用颜色区分身份等级的制度，随着唐文化与 
中国工艺美术的输入, 开始有大量的色彩出现在日本 贵族服饰中。中国服饰图案均具有象征性意义，除了 来自自然界中的植物动物图案外, 传统文化中衍生出 的龙、凤、祥云等区分尊卑的图案也传入日本，使日 本进入了使用花纹图案对服饰进行装饰的阶段。目前 和服上的诸多图案, 能明显感受到了中国传统文化的 影子，例如天皇的晃服上就存在日月星辰、龙风等中 式传统图案。

从史料来看, 韩国新罗时代与中原的汉人衣冠是 相同的, 后来的高丽与李朝时代, 整体还是保留了汉 服的特征。唐朝汉服的齐胸款式设计对穿着者身材包 容度极高, 汉服长度能将腿部的肢体变化完全掩盖, 掩盖了㻊拜行李时不必要的尴尤, 还能凸显穿着者的 端庄气质。由此可见, 汉服完全符合韩国人民的生活 与审美需求, 因此, 韩国基本完整的保留了汉服制度 与款式。如果说日本是在模仿中注入本土精神内核, 完成了和服的蜕变, 那么韩服则是对中国服饰制度与 款式的完整留存。

当日、韩对追随中国文化的狂热达到高潮时, 中 国元素与图案在日韩服饰中的设计中得到了充分的 借鉴与展示, 可以说, 日、韩传统服饰的建构是从对 中国传统服饰仿制到创造性重构的过程。

\section{3. 影视文化的传播对服装设计的影响}

影视文化是以电影、电视的方式进行的文化创造。 当今影视产业的现状呈现出良好的发展势头, 以影视 剧为载体的日、韩大众文化成功登陆中国并得以流行, 这对一些影视爱好者在服装的选择上有很大的影响。 一些服装品牌推出电视剧中角色所穿着的服装同款 或系列款, 或将电影中的角色形象作为服装设计元素, 再或是与电影合作推出联名款等。日韩文化一改过往 接受中国文化洗礼的情况, 以影视传播的方式开始了 对中国的文化反哺。

\section{1. 对风格设计的影响}

日、韩文化以影视剧为载体, 从上世纪 90 年代 进入中国后, 对中国大众文化产生了极大的影响。随 着日、韩影视剧在中国的热播, 两国服装都顺势涌入 中国市场成为新宠, 剧中的影视明星同款等俨然成为 时尚的代名词。甚至众多年轻人认为: “我看的不是剧 情, 而是男神、女神的爆款穿搭”。可以说, 日、韩文 化以服饰为载体, 通过影视传播的路径, 将本国文化 成功的输入到了中国。

在日剧中, 时常听到日本人对女生夸赞时用到的 词并不是 “漂亮、美丽” 等词语, 而是 “卡哇伊”, 也 就是可爱的意思。但日语里可爱和中文里的不同, 只 要是认为好的、喜欢的, 皆可称之为 “卡哇伊”。在日 本文化里, 任何东西都注重可爱, 即 “万物皆可萌”, 所以日系服装以减龄、可爱的风格居多。

而韩国服装风格则不同，宽松、舒适的廓形服装
和色彩饱和度高、大面积印花的服饰则更受喜爱。由 于受中国儒家思想的影响, 韩国对礼仪的重视程度也 是极高的, 重要的节日与场合都穿着正式, 故韩系服 饰在设计时多以适合行礼的宽松、舒适风格为主。

随着日、韩两国影视文化在中国的输入, 不仅促 进了日韩服饰文化的传播, 而且推动了三国在经济、 文化领域的合作与交流。中国各地服装市场涌现出以 日、韩风作为主打风格的服装品牌，各大线上购物平 台只要搜索 “日韩风” 等字眼, 便出现琳琅满目的服 装产品, 其销量也极为可观。甚至有大学生们将 “某 某剧同款、东大门同款” 作为自己的时尚风向标。可 见，日、韩影视剧的传播对中国服装市场风格的影响 之深。

\section{2. 对面料、款式设计的影响}

韩国设计师在新型面料的开发上具有技术性优 势, 他们善于生产染色后整理与高压复合面料, 使面 料更具多样性, 从而加强服装视觉冲击力。如 2019 年 热播的韩剧《德鲁纳酒店》, 女主李知恩每次出镜必换 服装, 短短 16 集的剧情中, 一共有 114 套服装造型。 丝绸、复合蕾丝、印花以及各种肌理面料, 加上精致 的发式与妆容, 将女主可帅气、可暗黑、可娇俏、可 甜美的多面性展示的淋漓尽致。电视剧刚播出不久, 李知恩同款就在各大服装平台热销, 成为韩剧带动服 装产业发展的又一成功案例。

在款式设计方面, 日本服饰一直是非常有影响力 的, 日本设计师总是很巧妙的将日本传统和东方禅意 相结合, 再加上西方的设计艺术与先进技术, 呈现出 精美绝伦的作品。日本不仅有享誉全球的国际大师三 宅一生、川久保玲和高田贤三, 也有代表大众文化的 日剧《校阅女孩河野悦子》, 剧中女主石原里美在职场 中的拼接外套、镂空毛衣、加上各种精美丝巾的点缀, 让人对原本一板一眼的职场穿搭有了新的灵感, 也体 会到日本女装设计的独具匠心。

此外, 剧中的服装与搭配能在中国如此受追捧, 不仅与新型面料、款式设计有关, 再得以影视剧中滤 镜的加持, 使氛围感美女的气质得以凸显。加上每周 一更的营销策略，不仅留与服装生产的时间，也拉长 了剧中服饰的生命周期, 从而达到影视传播与服装产 业双赢的局面。

\section{3. 对时尚元素设计的影响}

影视剧的跨文化传播是各种时尚新元素展示自 我的绝好时机, 通常在影视剧中最受关注的便是男女 主角的穿搭, 无论是新颖的肌理面料、还是绚丽多彩 的印花图案、或是精美绝伦的制作工艺都是设计师们 争相学习和模仿的对象。甚至在韩剧中 “初雪时, 要 穿漂亮的衣服去喝啤酒吃炸鸡” 也成为经典台词, 初 雪服装也一度成为时尚元素之一。可见, 服装作为传 统文化与现代精湛技艺结合的载体, 其附带的时尚元 
素成为时尚前进的推动器。

综上所述, 这些引领时尚潮流的时装设计师, 将 影视剧作为传播工具, 促进时尚元素的跨国传播, 不 仅提升了影片的观赏性, 而且对本国服饰文化传播起 到了积极推动作用, 这也是中国应向日、韩学习之处。 而中国从过去文化输出的主体成为目前文化输入的 客体, 其原因值得深思。在这个多媒体时代下, 传统 的跨文化传播方式早以不能满足现代文明的传播需 求, 应在原基础上增加影视、互联网、自媒体等新型 传播路径, 让中国文化传播路径更加多元化。此外, 对传播策略与内容也应更优化, 做到优质的内容、正 确的传播策略以及多元化的传播路径, 中国服饰承载 着中国文化再度成为东方明珠指日可待!

\section{4. 结论}

中国传统服饰文化, 一直如东方明珠般璀璨, 在 精神上追求无拘无束、人与自然的融合, 在形式上表 现为自然飘逸、宁静致远的传统服饰文化, 在世界各 国颇具影响力。随着历史的变迁, 中国服饰文化的影 响力逐步降低, 甚至受到了他国服饰文化的侵蚀。中 国服装产业未来如何做到可持续发展, 值得每一位服 装从业者深思。

深刻理解传统文化, 将民族精髓运用到现代设计 中是一个不易的过程, 未来设计师需要在发扬中国传 统服饰文化的同时, 融入创新元素、提高二次创作空 间，让服装设计手法更多元化。设计方向也应该是以 创新、满足美观与舒适以及绿色需求为主, 这需要设 计师们紧跟时代步伐, 开发出舒适的面料、时尚的款 式、既符合大众审美, 又能将中国文化理念发扬光大 的优秀作品。

综上所述，服装不仅是时尚元素与工艺的结合体， 更是饱含中国文化的载体, 同时是弘扬中国传统文化 的重要传播路径。在这个多媒体时代, 服饰文化的传 播不容忽视, 希望中国服装能承载着中国文化, 以多 种传播路径走出去, 扩大中国文化的时尚号召力与世 界影响力!

\section{REFERENCES}

[1] Teng,J.(2011) History of cultural exchange between China and Japan. Peking University Press,Beijing.

[2] Jiang, L.(2006) A comparative study on the inheritance and wearing status of national clothing in China,Japan and South Korea. Journal of Suzhou University (Engineering Edition), 03:73-75.

[3] Jiang,X.F.(2006) A comparative study on the attitudes and selection factors of Chinese, Japanese and Korean towards national costume. Journal of Donghua University (Social Science Edition), 03:37-40.
[4] Jing, M.Y.(2011) The changing characteristics of the comparative advantage model of China, Japan and South Korea and Its Enlightenment. Northeast Asia Forum, 20(02):50-60.

[5] Zhang,Y.Y.(2019) Differences and similarities of Chinese, Japanese and Korean cultural resources. People's Forum, 30:128-129. 